\title{
Transforming an agricultural trade organization: a system-dynamics-based intervention
}

\author{
Michael Weber $^{\mathrm{a} *}$ and Markus Schwaninger ${ }^{\mathrm{b}}$
}

\begin{abstract}
Michael Weber is senior assistant at the Swiss Federal Institute of Technology, Zurich, Switzerland. His research is focused on corporate finance and strategic issues in Swiss agribusiness firms. Before he took up his position at the Swiss Federal Institute of Technology he worked in business consulting for six years (consulting and restructuring of firms in the sectors construction, industry and service).
\end{abstract}

Markus Schwaninger is Professor of Management at the University of St Gallen, Switzerland. His research is focused on managerial cybernetics and system dynamics, applied to issues of organizational intelligence, management systems, and to the design, transformation, and learning of organizations. He is author of 130 publications in six languages on systemic aspects of management, including Organizational Transformation and Learning, A Cybernetic Approach to Management (Wiley, Chichester, 1996, with

\begin{abstract}
The management of agricultural trade organizations in Switzerland is characterized by completely new entrepreneurial challenges due to a progressive opening of agricultural markets and a corresponding reform in the state's agricultural policy. The need for well-suited strategic management tools has suddenly become manifest. Given this background, the intervention described in this article took place in a division of a union of cooperatives in the Swiss agribusiness, which is a typical example of a small to medium-sized enterprise (SME). The aim of the project was to search for possible ways to sustain the viability of the division in the future. The intervention started with the development of an overall descriptive network-type model of the strategically relevant issues faced by the division. A system dynamics (SD) model was built as a decision support tool for one of two crucial strategic issues: the organization of the distribution system. Based on the insights derived from model-building and simulation, the management team changed its shared mental model of the issue at hand, achieving a deeper understanding of the situation faced, the options available and their implications. Thereupon, they have started to reorganize the whole distribution system. In sum, the modeling and simulation activities undertaken had a powerful trigger function in the process by inducing organizational learning at a very fast pace. Copyright (c) 2002 John Wiley \& Sons, Ltd.
\end{abstract}

Syst. Dyn. Rev. 18, 381-401, (2002)

\section{Issues}

The system-dynamics-based intervention reported in this article took place in the Farm and Mill (FM) division of the Landwirtschaftlicher Genossenschaftsverband Schaffhausen (Association of Agriculture Cooperatives Schaffhausen) (GVS), Switzerland. GVS can be classified as a typical small to medium-sized enterprise (SME). The intervention was realized in a consulting project directed by the first author of this paper. ${ }^{1}$ Before we describe the project and its outcomes in details, we will give an overview of the issues faced by the agricultural sector in general and by the firm under study in particular.

\section{Issues faced by the sector}

The economic environment for agricultural trade in Switzerland has changed substantially since the beginning of the 1990s. This is due to a far-reaching

\footnotetext{
a Agricultural Economics, Swiss Federal Institute of Technology, CH-8092 Zurich, Switzerland.

b Institute of Management, University of St Gallen, CH-9000 St Gallen, Switzerland

* Michael Weber, Agricultural Economics, Swiss Federal Institute of Technology, CH-8092 Zurich, Switzerland; E-mail: michael.weber@iaw.agrl.ethz.ch

System Dynamics Review Vol. 18, No. 3, (Fall 2002): 381-401 DOI: $10.1002 / \mathrm{sdr} .254$

Received November 2001 Copyright (C) 2002 John Wiley \& Sons, Ltd.
} 
co-authors) and six books in German, published with Campus, Frankfurt; Duncker \& Humblot, Berlin; and Haupt, Berne. opening of Swiss agricultural markets and a corresponding reform of Swiss agricultural policy-including a reduction of internal support and export subsidies. The consequences have been falling product prices and farm incomes, as well as major structural adjustments in the farm sector (Schmid 2001; Bickert 2001). This development has also had far-reaching effects on agricultural trade organizations, such as decreasing demand for agricultural input factors, lower prices, higher competition, and increasing variation of all relevant economic factors (Bickert 2001, p. 16). Moreover, the technological development in relation to electronic trade induces important threats to traditional forms of agricultural trade (due to higher transparency, new competitors etc.). Altogether the pressure to adjust structures in agricultural trade is becoming very high. In the future, this development will continue. The next steps of agricultural policy reform are in sight (see for example BLW 2001). In addition, a progressive alignment of the whole Swiss economy to the European Union (EU) — which is likely — will lead to open markets and more competition.

The situation for the management of agricultural trade organizations in Switzerland is characterized by completely new entrepreneurial challenges, with high costs of wrong choices and irreversibility of many decisions. The pertinent managerial issues and problems are complex. Under such conditions, strategic management becomes crucial to sustain the viability of the organizations concerned (Espejo et al. 1996; Malik 1996; Schwaninger 2001). The need for well suited strategic management tools is suddenly manifest in agricultural trade firms, for most of which the concepts and instruments of strategy are new.

\section{Issues faced by the firm in focus}

GVS is a union of cooperatives of farmers in north-eastern Switzerland, the purpose of which is to join forces with the trade and transportation sectors. This organization has different divisions, which are quite diverse (e.g. agricultural trade, wine trade, trade in farm machines, trade in gasoline, transport). The turnover of GVS as a whole lies in the order of 90 million Swiss francs (ca US $\$ 55$ million). The FM division trades agricultural inputs (e.g., fertilizers, seeds, pesticides, compound feed) and products (e.g., grain, potatoes) in the up and down streams of the agribusiness chain. In addition, there are also some new trade products that should be pushed in the future (e.g., horse feed). The turnover of the division is about 20 million Swiss francs (ca. US \$12 million).

In the last few years, the performance of the FM division has not been satisfactory, but the other divisions have been strong enough to cover the financial needs of the whole organization. In the future, this will no longer be possible because of a recent unbundling of the specific activities. The FM division will be obliged to sustain its viability on its own. The situation of the 
FM division is characterized by some specific factors that are important for the future development:

- The farm sector in north-eastern Switzerland is changing in part from crop production to animal production as a result of the ongoing reforms in Swiss agricultural policy. This leads to a different demand structure for agricultural inputs and products to be traded.

- The most important supplier of agricultural inputs, hereafter referred to as AgCoop, is the strongest competitor in the other fields of activity. This firm is about 50 times bigger than GVS and, consequently, it has substantial business strengths compared to GVS. GVS is successful where it can count on the cooperation of AgCoop and unsuccessful where it competes with AgCoop. In addition, potential threats are highest in those businesses where GVS is most successful today.

- The FM-division has had a well-defined market region to date. There are relatively few competitors in this region. In the north, there is the border with the EU and the market region of the biggest competitor is to the south. As a consequence of the rising competition (see Issues faced by the sector above), this market situation of relative protection could change very fast.

- Because of the prosperous sister divisions and the habit of cross-subsidizing in the past, almost no sense of urgency exists in the FM division about improving its own performance.

- There are almost no explicit tools or processes for taking strategic decisions (for the following reasons: lack of resources; lack of methodical know-how; no need for such instruments in the past). Nevertheless, there is a need for such support tools.

These specific factors were considered in the framework of the systemdynamics-based intervention.

The FM division of GVS faces the need to transform its organization, given the turbulence of its environment. In this situation, the management has to cope with overwhelming complexity. Since to date almost no tools have been applied in the FM division that enhance planning and learning under such complexity, there is a need for a methodology to help the actors deal with the complex issues they face. Under these circumstances, the management of the FM division initiated an intervention project for organizational transformation, together with the external facilitators, led by the first author of this paper.

The article is structured as follows: first we give a brief outline of the methodology used and the intervention process realized. Then, we will describe the System Dynamics (SD) model that we developed, during the intervention process, as a decision-support-tool. Next we will elaborate on what has been learned from the model and how the model has influenced the process. Some reflections on the process and an outlook on the transformation of the firm will conclude the article. 


\section{The project}

\section{Methodological basis}

The purpose of this section is to provide a reasonable overview of the methodology used while leaving enough room to discuss application-related issues in a case study for the ensuing sections.

Based on Espejo's and Schwaninger's conceptual and empirical work, an integrative methodology has been developed to help actors in dealing with complex issues in organizations and society (Espejo 1993; Schwaninger 1995, 1997). The focal purpose of this methodology, called Integrative Systems Methodology (ISM), is to help actors in organizations and society attain requisite variety ${ }^{2}$ (Schwaninger 1997, p. 113). ISM has two methodological roots. These are, on one hand, methodologies from the structuralist-functionalist tradition, namely System Dynamics (Forrester 1961) and Management Cybernetics (Beer 1979, 1981; Espejo 1993), and hermeneutic-interpretative methodologies on the other, Soft Systems Methodology (Checkland 1981) and Methodology of Network Thinking (Gomez and Probst 1999) in particular. An overview of the methodology is given in Figure 1. ISM conceives the problem solving process through two loops, a "content loop" and a "context loop" (Schwaninger 1997; Schwaninger and Pérez Ríos 1998, p. 25ff). The "content loop" deals with the "substance" of the issues at hand. It involves the use of factual knowledge and issue-specific methods, together with technical and conceptual skills. The "context loop" deals with the organizational context in which the issues at hand are embedded. The two loops are only separated for the purpose of analysis. In fact, they are intertwined and they often show overlaps. The two loops revolve iteratively around a set of operations. In the overview (Figure 1), a set of four operations is distinguished; to the operations are: modeling; assessing; designing; and changing.

The more detailed layout of ISM essentially combines the methodologies of system dynamics modeling, with its qualitative and quantitative components (content loop) and cybernetic modeling (context loop). It also introduces the issue of model validation as a crucial feature of both qualitative and quantitative model building. Knowledge elicitation and mapping tools, for the content loop, are standard system dynamics tools, however enhanced, at the qualitative end, by a set of heuristics (For details and practical examples, see Schwaninger 1997):

- to frame the overall purpose of and the perspectives (i.e., stakeholders) relevant for the model;

- to ascertain the specific objectives related to each one of these perspectives;

- to specify the key success factors for attaining these objectives.

The last of these provides a provisional list of parameters and variables. The tools for the context loop are standard organizing models, the Viable System Model (Beer 1979, 1981) in particular. 
Fig. 1. Integrative Systems Methodology -an overview; source Schwaninger (1997)
Fig. 2. Process model for the intervention; after Pérez Ríos and Schwaninger (1996)

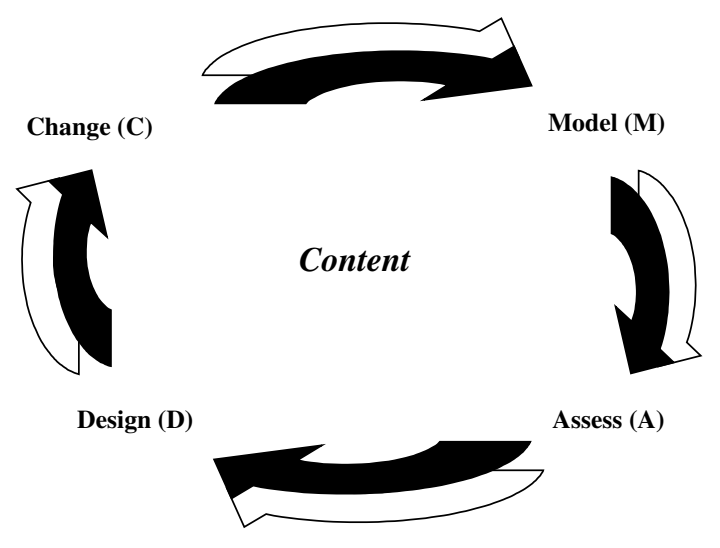

Context

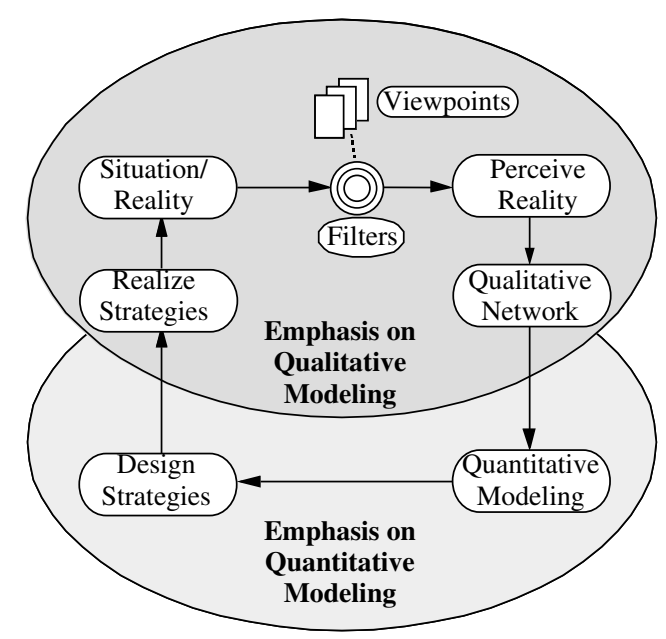

For details about validation procedures, see, in particular Barlas, (1996) and Forrester and Senge (1980).

Content LEVEL At the content level, the intervention in the project reported here followed a concrete process model based on ISM (Figure 2). The process combined qualitative and quantitative modeling. Instead of running through the whole loop depicted in Figure 1 twice, as was the case in earlier applications (Schwaninger 1997), the following procedure was used. First, a qualitative mapping of the issues at hand in form of a network of feedback loops was undertaken. This was followed by the implementation of a quantitative system dynamics model, and the design of strategies on the basis of simulations. This 
Fig. 3. Overview of the intervention process procedure was chosen because in the project an almost ideal situation of a high frequency of interaction between client and consultant was possible, including an active contribution from the client to the elaboration of the quantitative model. This was particularly favorable in the situation of the SME under study, which had little experience in strategic management. At this point, strategies are being implemented and we have started to assess their impact on the evolution of the firm.

Context LEvel The second loop of ISM concerns the organizational context into which the issue at hand is embedded. This part of the ISM process deals with a higher-order aspect (Schwaninger 1997). In principle, the nature of the organizational context defines, and delimits, how good or effective a solution at the object level (i.e. at the level of the content of the issue at hand) can be. We will only be able to report very briefly on how the organizational context was diagnosed and redesigned.

\section{Overview of the intervention process}

A sequential picture of the concrete procedure used in the intervention process is given in Figure 3. Based on the idea of feedback-driven exploration (Schwaninger 1996), three workshops with the participants of the firm were organized. The workshops consisted of work phases in subgroups alternating with discussions and synthesis in the whole group. In the process, techniques such as "brainstorming" and a kind of "nominal group technique" (Flood

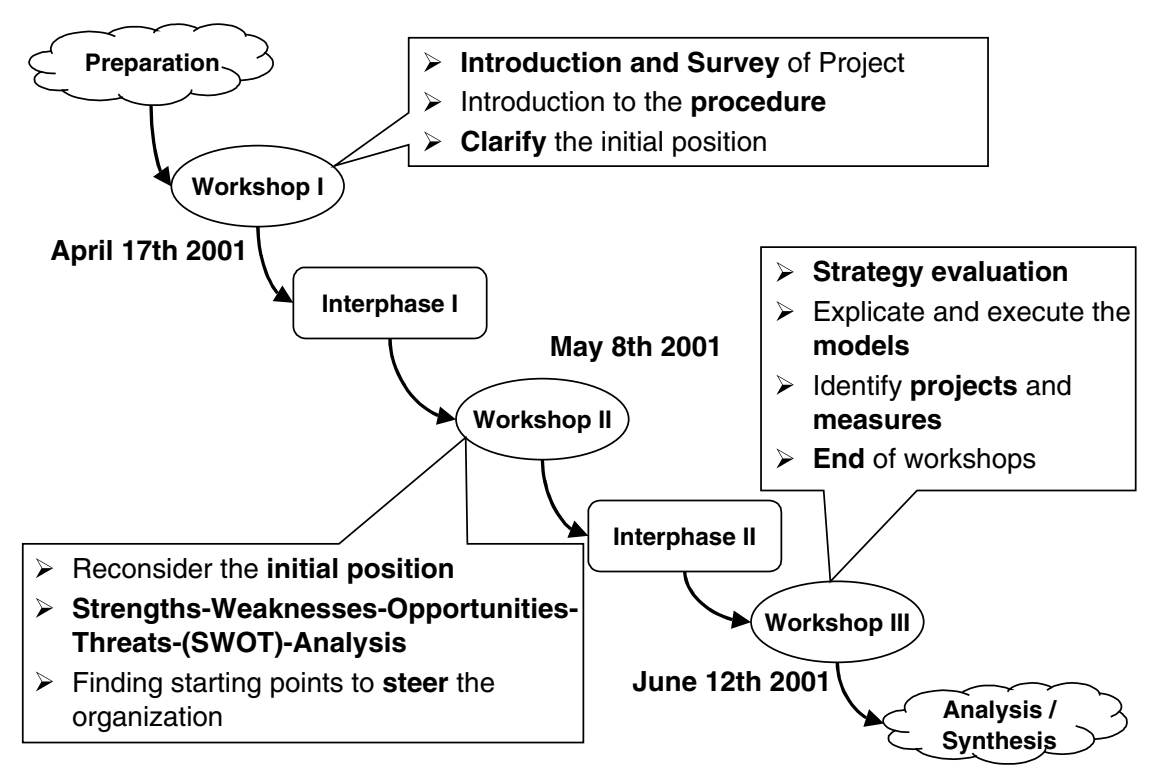


1999, p. 124ff) as well as conventional tools of strategic analysis, e.g., strengths-weaknesses-opportunities-threats (SWOT) analysis, were used.

The participants in these workshops were the chairman of GVS, the Chief Executive Officer (CEO) of GVS, the Chief Operating Officer (COO) of the FM division, one person from divisional marketing, one person from the divisional sales force, and one person from the divisional administration. The team of facilitators (Michael Weber and Hansjörg Schmid from the Swiss Federal Institute of Technology) engaged in preparatory work (e.g., workshop preparations, analysis of the firm, preliminary SD models), evaluations and synthesis of the workshop results before, between and after these workshops. The intermediate steps taken by the team of facilitators were always realized in alignment with, and based on feedback from, the internal team of the firm. This was part of the validation procedures.

The intervention process specified-among others-two main strategic challenges to cope with in the future:

- The actual range of traded and produced products is very wide. It is not clear which is the optimal mix for the future.

- The present structure for the distribution of agricultural inputs from the FM division to farmers is expensive and, under several approaches, has not led to the desired level of professional customer service (e.g., possible business hours, technical competence of sales personnel at small local points of sale).

During the assessment stage of the intervention process, these two main challenges where treated separately with different tools for comprehending the dynamics, simulation and exploration of scenarios. This division of the challenges presented makes sense, because it allows for more depth in the analysis and a search for customized solutions (Gomez and Probst 1999; see also Probst and Gomez 1992). In the case of the product range, conventional planning tools were used (e.g., an Excel ${ }^{\mathrm{TM}}$-based tool for simulating environmental changes and their financial implications for the firm). In the second case, we used an SD model as a decision support tool, which will be described in the next section.

\section{A system dynamics model as a decision support tool}

\section{Outline}

The construction and use of the SD model was a crucial part of the whole ISM intervention process. It started with the development of an overall descriptive network-type model of the strategy-relevant issues faced by the FM division. This was necessary to elicit the mental constructs of the actors and to clarify and structure the debate about the situation that was seen as problematic 
Fig. 4. Overview of the qualitative map of the FM division

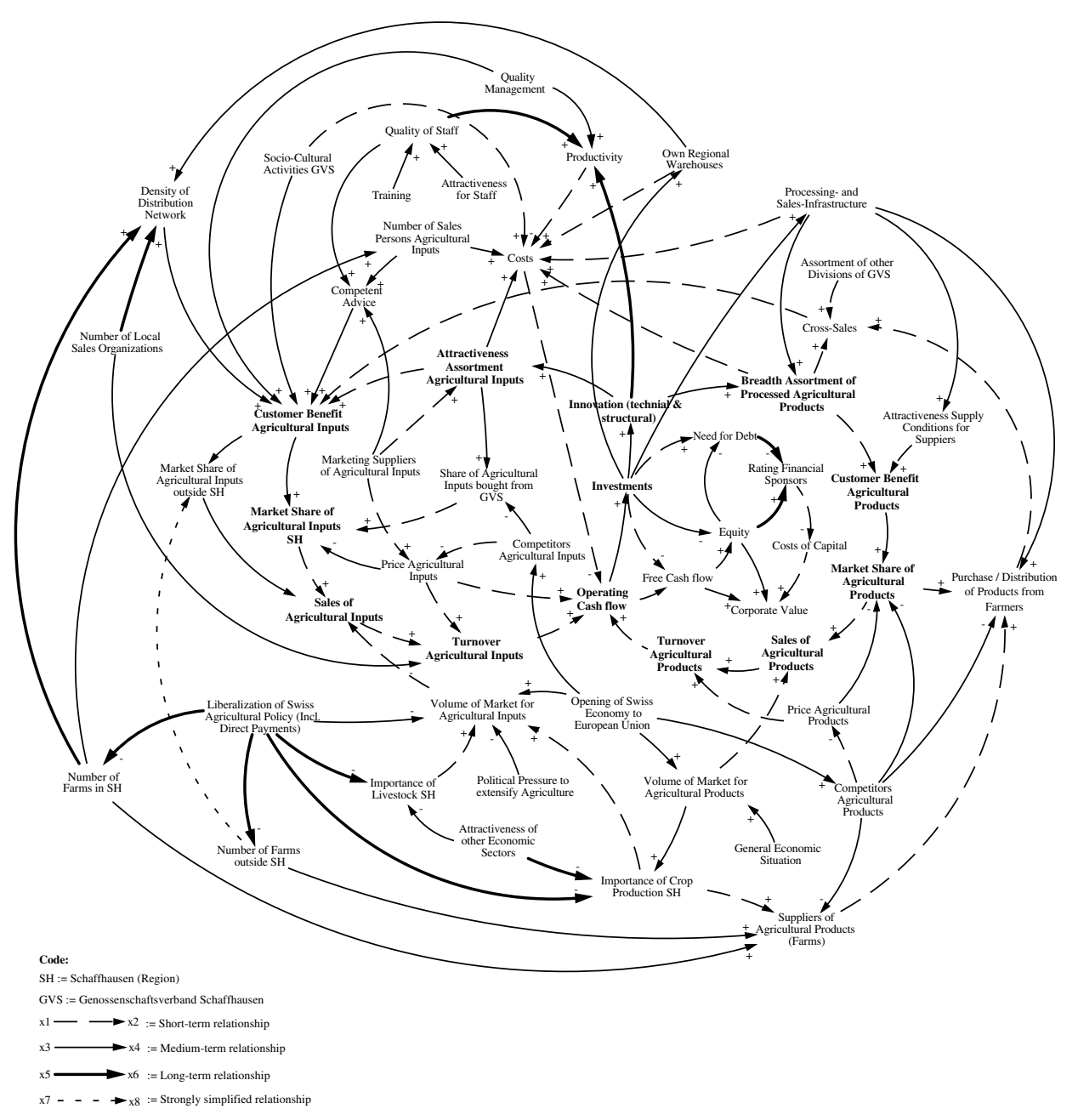

(Vennix 1996, p. 109). Figure 4 gives an overview of the qualitative model ("map of the situation"). ${ }^{3}$

The make-up and analysis of this network diagram triggered the two main strategic questions for the FM division that were mentioned in the paragraph above: optimal mix of products and structure for the distribution of agricultural inputs.

During the intervention process, some actors came up with the idea of eliminating one stage in the flow of agricultural inputs from the FM division to the farms. The following question was our starting point for the development of the SD model: "Would it be possible to improve the situation of the FM division and that of the customers if the existing local points of sale were omitted 
and replaced by a direct delivery service for all agricultural inputs?" The underlying dynamic hypothesis was: "If there is no change in the distribution structure for agricultural inputs, customer satisfaction will deteriorate and the economic situation of the FM division will degrade even more than at present." This expected decline would result from the foreseeable changes in the economic environment. First of all, the fast technological development opens up new possibilities to trade agricultural inputs and goods via electronic markets. Second, the liberalization of agricultural policy gradually entails more open markets for trading agricultural inputs and goods across borders. These two factors - among others-lead to higher market transparency, more competition, more available information and sales services, and the possibility to buy and sell 24 hours a day. In addition, the prices of all products are also expected to fall. On the basis of these considerations, a higher level of customer service and strict control of costs for the FM division were perceived as crucial factors for future success. Both aspects were tightly connected with the issue of the distribution structure. If the FM division does not change anything, customer satisfaction and the division's own performance will deteriorate in the future.

In the course of the intervention process, the team decided to build a decision support tool to find answers to our question. An SD approach was chosen for the following reasons (see also Vennix 1996, p. 105ff; Sterman 2000, p. 79ff; Barlas et al. 2000, p. 51):

- The issue at hand was dynamically complex because of the number of feedback processes involved.

- The decisions of the management on this issue would have grave long-term implications for the whole structure and performance of the FM division.

- The problem was strongly linked to stock and flow processes.

- It would be possible to generate a reference mode of behavior.

Figure 5 shows the subsystem diagram of the model.

The SD model developed represents the supply chain of the FM division for agricultural inputs. The model was conceived for a time horizon of one year with 250 days of work. This allowed for the measurement of effects such as delivery time, cost, price changes and changes in market share.

The model distinguished between two different products:

- a herbicide (pesticide for weed-killing);

- a compound feed for cattle breeding.

The aim was to test the effects of a shut down of the product distribution through local points of sale and the implementation of a direct delivery service for all agricultural inputs. The complete model diagrams and equations are available from the authors. 
Fig. 5. Subsystem diagram of the distribution structure of the FM division for agricultural inputs

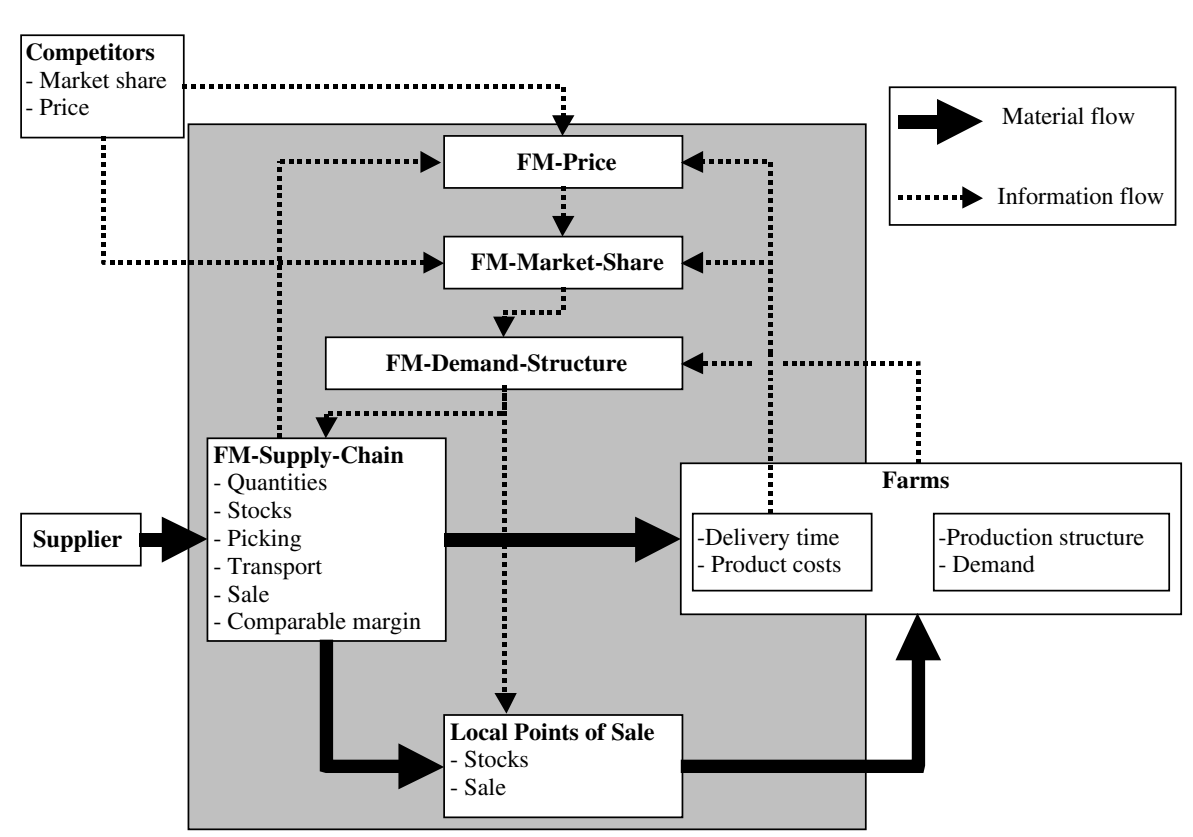

In Figure 6, the core part of the model in stock-flow format is displayed. The process involves a stock of incoming products (Entrance Inventory), which is fed by arriving materials and drained by the picking of the two possible ways of product delivery (directly to the farmer and via the local points of sale).

The basis for the construction of the model is a generic model of the stock management structure (see Sterman 2000, p. 663ff and p. 709ff). The model consists of five components described below.

ORDERS AND MATERIALS SUPPLY LINE Orders of material are triggered by the demand from farmers. The demand is a function of:

- the area farmed or the animals bred;

- the intensity of production;

- the initial market share of the FM division;

- the seasonal distribution of the demand (determined by production cycles which are caused by nature).

The delivery of materials is a function of the demand and the delivery time of the supplier (sufficient stocks can be assumed).

FM SUPPLY CHAIN The FM supply chain shows the two possible ways of distribution along the two different channels (direct delivery and delivery via the local points of sale; see Figure 6). After the arrival of the material, the 
Fig. 6. Stock and flows representation of the core part of the model (FM supply chain)

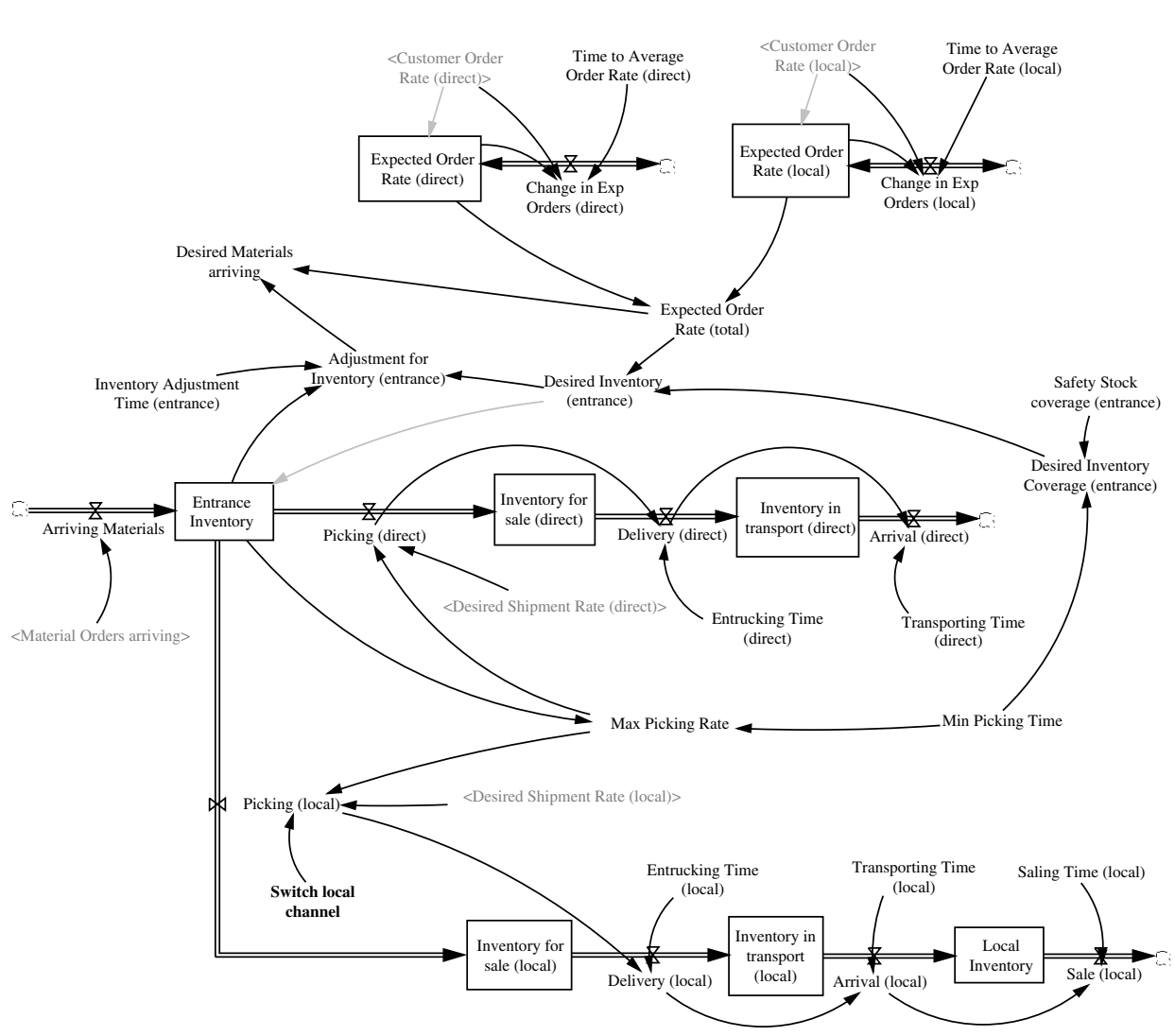

picking of the individual orders (customers or local points of sale) and the transport, either to the customer or to the local points of sale, are completed. There is a switch that permits turning off the distribution to the local points of sale. In this case, all the products are distributed directly to the customers via a direct delivery service.

FM SALES AND COSTS In this part of the model, the turnover and the direct costs of distribution (purchase of materials, upkeep and repairs, electricity, picking, packing, administration, shipment ${ }^{4}$ ) are determined. The aim is to calculate a contribution margin that allows a comparison of the financial attractiveness of different policies for the FM division.

Competitors In the competitor part of the model, the market share of the FM division is determined. It is calculated as a function of price differences between the competitors and the FM division, as well as of the delivery time of FM division. 
Customers In this part of the model, the product price for customers and the delivery time are calculated. The comparison of different scenarios shows which option is more attractive for the farmers.

\section{Model parameters}

The data used for the simulations is based on information about the situation of the year 2000, obtained from the FM division. The essential parameters used in the model are given in Table 1.

The demand for the herbicide product changes over the year because of production cycles that are caused by nature. This leads to strong changes in the supply chain during the delivery period. The other product, the compound feed for cattle breeding, has a basically constant demand throughout the year.

During the preparatory work and during the workshops, scenarios with different assumptions for the future values of the parameters were simulated. This gave the participants of the workshops a good idea of the behavior of the model and the sensitivities.

\section{Validation}

The validation of system dynamics models has two important aspects: structure validation and behavior validation (Barlas 1996). Structure validation is about warranting that the model's internal structure is a sufficiently accurate description of the real system, with respect to the issue of interest. Behavior validation means that the output behavior of the model reproduces closely enough the dynamic behavior of the real system under study (Barlas et al. 2000, p. 53).

In the validation process, different structure validity tests were carried out (e.g., parameter-confirmation test, direct extreme-condition test, dimensional consistency test, stress testing, behavior sensitivity test, phase relationship test; see Barlas 1996, p. 189ff). The model was improved continually in the course of this validity testing. The accurate replication of the patterns for the last year was tested for checking the behavior validity. The results of this test led to a discussion with some of the FM division managers on the adequacy of actual stock management for the modeled herbicide product. This was due to persistent, albeit small, differences between the observed stocks and the modeled stocks. Finally, we agreed (a) that the differences must be due to insufficient stock management and (b) that stock management for the herbicide product would be checked within the scope of the started project for the reorganization of the distribution system (see below).

Dynamics of the distribution system

In this section we will present some of the dynamic patterns which the SDmodel generated. Figure 7 shows a time plot of the demand and delivery 
Table 1. Essential model parameters

\begin{tabular}{lcc}
\hline Parameter & Product \\
\cline { 2 - 3 } & Herbicide & $\begin{array}{c}\text { Compound feed for } \\
\text { cattle breeding }\end{array}$ \\
\hline
\end{tabular}

Demand

Demanded quantity

Average quantity per delivery

Market share in own market region (at start)

Changes in market share

Shares of distribution per channel (at start)

Seasonal distribution of demand

Delivery time supplier Product price for farmer

Supply chain
Time for picking the
orders
Time till delivery
Time for transportation
Advance booking by FM
division
Considered cost
components

Supply chain

\author{
1,302 liters \\ Direct:16.5 liters \\ Local: 100 liters \\ 95 percent \\ No changes during the \\ simulation because of \\ single buys in each year \\ Direct: 19.0 percent \\ Local: 81.0 percent \\ 95 percent of the demand is \\ sold within 2-3 weeks; \\ whole application \\ duration is 8 weeks \\ 1 day \\ Direct: CHF 73.72 per \\ liter + CHF 15 per delivery \\ Local: CHF 80.32 per liter
}

0.25 days

Direct: 0.25 days

Local: once a week to the

local point of sale

0.25 days

100 liters on day 40

Picking, energy, maintenance and repair, direct administration, packaging, transportation
74,782 kilograms

Direct: 1,532 kilograms Local: 1,273 kilograms

50 percent

Changes are a function of price differences between competitors and of the realized delivery time

Direct: 77.9 percent

Local: 22.1 percent

Constant over the year

1 day

Direct: CHF 0.779 per

kilogram + CHF 15 per delivery

Local: CHF 1.025 per kilogram

0.25 days

Direct: 0.25 days

Local: once a week to the local point of sale

0.25 days

No advance booking

Picking, energy, maintenance and repair, direct administration, packaging, transportation

quantities via direct delivery versus local points of sale, for the herbicide product (see Table 1). This was the base case used before the consequences of a shut-down of the local points of sale were simulated. The plot highlights the very short time period of high demand and exhibits the consecutive patterns of delivered quantities for the two distribution channels.

Figure 8 plots the average delivery times for the herbicide product with and without the distribution via the local points of sale during the high 
Fig. 7. Demand and delivery (direct and local; herbicide)
Fig. 8. Delivery time (herbicide)
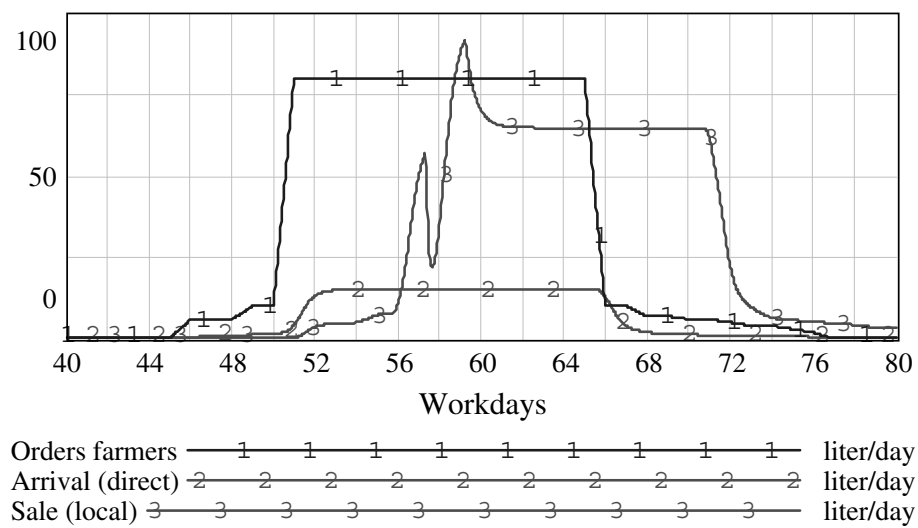

season. The delivery time shoots up at the beginning in both scenarios, despite advance bookings by the FM division. On the following days, a marked difference between the delivery times of the two scenarios opens up. This means that the farmers benefit from the fact that all products are delivered via the direct service.

The cumulated costs for the farmers (= customers) are shown in Figure 9. The figure plots both situations, with and without the distribution via the local points of sale. The farmers pay less for the herbicide product if all goods are delivered directly and the local points of sale are turned off. The difference in the possible product price lies at about 4.60 Swiss Francs per liter, which is strikingly high.

Figure 10 shows the same scenarios for the herbicide product, but from the view of the FM division. The case with a complete delivery of all herbicide products via the direct delivery service generates a higher contribution margin (defined as price minus costs for picking, packaging, transportation, energy,

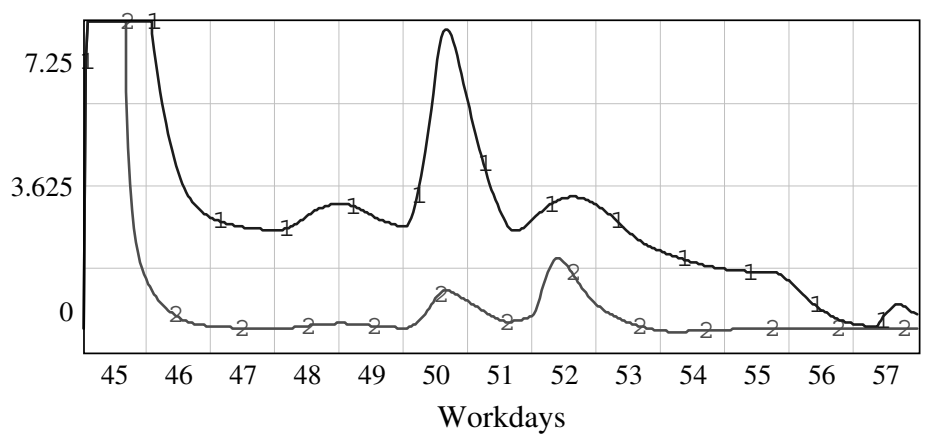

Average delivery time (local \& direct) $\quad \begin{array}{llllll}1 & 1 & 1 & 1 & 1 & 1\end{array}$ Average delivery time (all direct) $\begin{array}{llllllll}2 & 2 & 2 & 2 & 2 & 2\end{array}$ Day 
Fig. 9. Cumulative costs for farmers (herbicide)

Fig. 10. Contribution margin for FM division (herbicide)

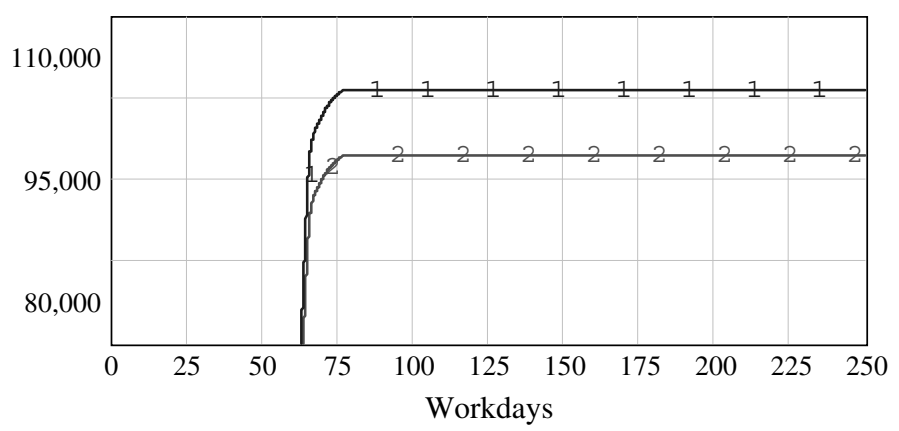

Costs for farmers (local \& direct) $\begin{array}{lllllll}1 & 1 & 1 & 1 & 1 & \mathrm{CHF}\end{array}$
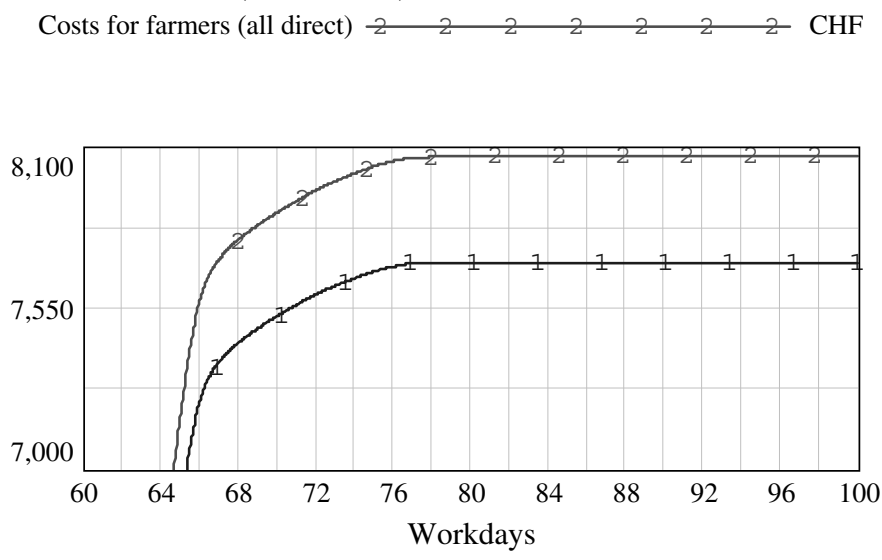

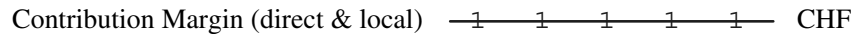
Contribution Margin (all direct) $\begin{array}{llllllllllll}2 & 2 & 2 & 2 & 2 & 2 & & & & \end{array}$

maintenance and repair, direct administration) for the FM division. The difference per liter of the product lies at about 0.07 Swiss Francs. This is not much. Sensitivity checks also showed that this difference is quite sensitive to changes in the assumptions for the scenarios. This means that cost control is crucial for the FM division.

Figure 11 shows the market share of the FM division for compound feed under different price scenarios (hypothetical). The market share is quite constant in the base case scenario, while it changes significantly if the competitors change their price policy. The first scenario-"price shock 1 "- includes a limited price reduction by competitors from day 25 to day 100 (maximum: 20 percent reduction). In this scenario, GVS reacts with a price reduction of 14 percent maximum during days 25 to 82 . Prices are then readjusted by competitors to the original level on day 101. The price of GVS is readjusted with a first-order adjustment process (20 days of adjustment time). The second scenario- - price shock 2"-is characterized by a constant price 
Fig. 11. Price shocks and market share of FM division (compound feed)

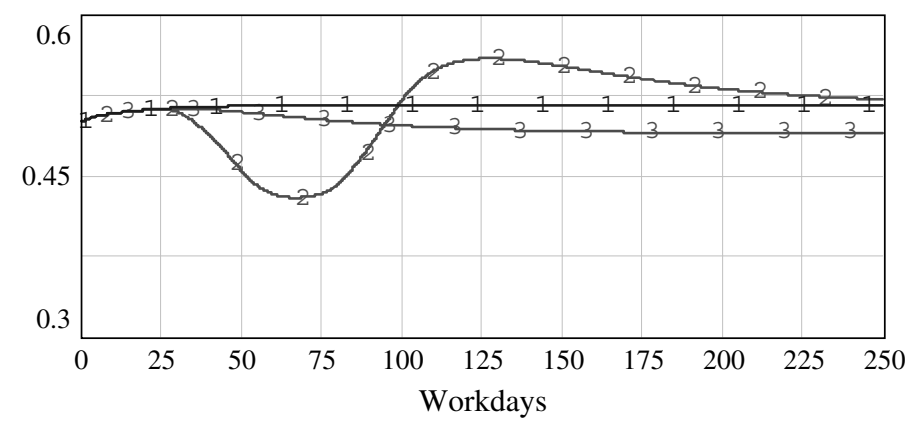

$\begin{array}{lllllllllllll}\text { Market share (base case) } & 1 & 1 & 1 & 1 & 1 & 1 & 1 & 1 & 1 & 1 \\ \text { Market share (price shock 1) } & & 2 & 2 & 2 & 2 & 2 & 2 & 2 & 2 \\ \text { Market share (price shock 2) } & 3 & 3 & 3 & 3 & 3 & 3 & 3 & 3 & 3\end{array}$

reduction on the part of the competitors from day 25 to day 250 (maximum: 18 percent reduction). The simulations show that the market share is sensitive to price changes on the part of the competitors (the examined type of compound feed is a standardized commodity).

The market share of GVS recedes as competitors reduce their price temporarily. As they readjust the price level upward, GVS enjoys a temporary price advantage and thus books a market share gain (readjustment time for price is 20 days; readjustment time for market share is 20 days; both are first-order adjustment processes). Thereafter, the market share advantage of GVS fades.

\section{Insights and decision}

The use of the SD model during the intervention process led the participants of the FM division to a deeper understanding of the dynamics generated by the distribution structure for agricultural inputs. They learned from the model that turning off the local points of sale could have positive economic effects for both the farmers and the FM division. The savings for the farmers are striking, while those for the FM division are relatively small and quite sensitive to changes of model parameters. But, if the economic environment changes in the way expected, the savings for the farmers are the most important aspect for the FM division in sustaining its market position in the future. This is the case, independent of the cost savings for the FM division.

On the basis of the results of the SD simulations, ${ }^{5}$ the participants decided to start a project for the reorganization of the distribution system for agricultural inputs. This project will be quite demanding because there are additional stakeholders who will be involved, e.g., managers of the local points of sale, farmers, suppliers and logistic staff. In this process, the results of the SD simulations will supply good arguments to show the positive effects of a change. 
Looking back on the whole intervention process, one can clearly identify that the SD model had a trigger function. At the beginning of the assessment stage (see Figure 1) in Workshop 2 (see Figure 3), most participants were very skeptical about the idea of turning off the local points of sale and distributing all agricultural inputs via direct delivery. A substantial discussion about assumptions and important factors for future distribution emerged on the basis of the simulation results. At the end of this discussion, all participants agreed to define and realize the restructuring project. Thus, the model unambiguously had an important influence, as will be analyzed in more detail in the next section: It changed the mental models of the persons involved and triggered organizational learning. This is probably the most valuable impact that the whole intervention process realized.

\section{Reflection and outlook}

The whole process was evaluated after the intervention with a questionnaire completed by the participants of the workshops. These give a positive assessment of the intervention. The composition of the group was quite heterogeneous (hierarchically and functionally). Nevertheless, 100 percent of the participants considered the quality of the interaction during the intervention as good or very good. Most of them also stated that they had gained new insights into the strategic situation of their division and the process of developing a strategy. As far as judgment of the single steps of the applied methodology is concerned, all steps were generally considered to have been effective. However, a third of the participants felt they were short of time to carry out some steps in the process (especially the steps of the analysis of the initial position of the firm).

Most of the participants expected that the intervention would lead to a change in the FM division (see Figure 12).

From the perspective of the facilitators, the procedure based on ISM was very helpful in this case study. We noticed during the intervention, however, that the participants needed quite a lot of time before a sense of urgency for change arose. This appears to be due to the past practice of cross-subsidizing in the organization. We are convinced that it is important for future applications of ISM in SMEs to summarize the results of the "surfacing" of relevant issues in the "modeling" phase (see Figure 1) in a more "drastic", black-or-white manner than in the case reported here. This kind of provocation is likely to lead to more in-depth discussions early on than those that we achieved in this intervention, and we would expect a faster grasp of the issues at hand within the whole group of participants. This seems particularly important in an SME, where not all the participants involved are familiar with the kind of information needed to build a strategy for their firm. 
Fig. 12. Answers of participants

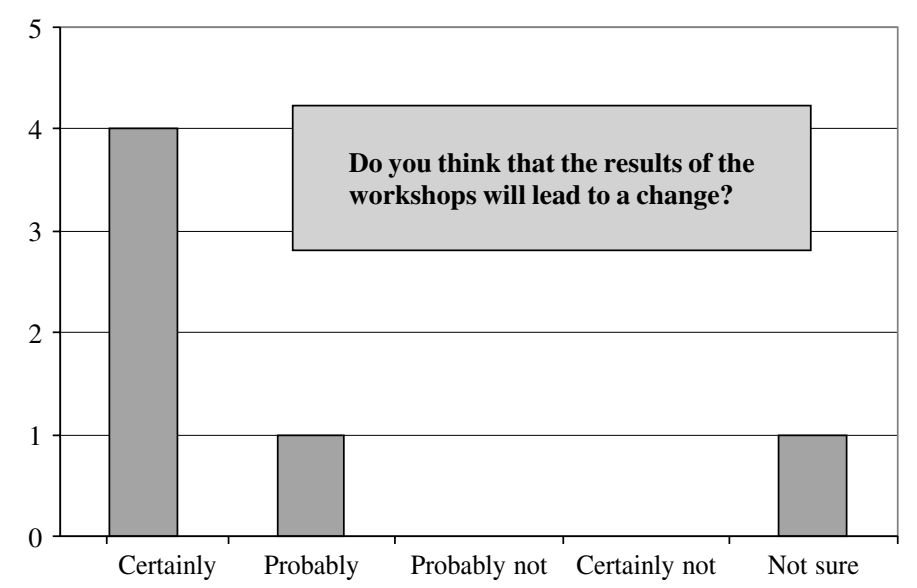

In retrospect, the development of an SD model as a decision support tool during the intervention was an excellent choice: the model and the simulations delivered much valuable information and triggered the initiation of structural change. The SD model was a very efficient tool for structuring the discussions in the third workshop. These discussions about the model and its underlying assumptions triggered a fertile exchange of views and ideas between the participants. In sum, a very valuable "negotiated understanding” (Burr 1995, p. 5) of the actual situation and the need for action took place. However, the development of this tool with all the data gathering and validation involved was very time consuming for the facilitators. Given the time pressure imposed by the changing context and the limited time of the internal team members, a total span of less than two months for the whole intervention was the utmost achievable in this case. However, we also estimate that this amount of time can be reduced significantly in future interventions (more experience in model building, applications in similar firms). Altogether the building of an SD model during the intervention in an SME is a practicable and helpful step. However, the following conditions and restrictions have to be taken into account:

- Besides SD skills, the facilitators need to have substantive knowledge about the business in which the intervention is take to place. This enables the group to approach the crucial questions fast and to search for the right data.

- In an SME it is usually not possible to build a quantitative model for all entrepreneurial aspects of the firm. Consequently it is important to choose the most relevant entrepreneurial issues (for example, through qualitative modeling) and to concentrate the quantitative modeling on these issues. The connection back to the other issues has to be made by means of the qualitative model. This is not without its dangers, but is necessary if the availability of resources for strategic issues is limited. 
- Many SMEs will find it very difficult to develop all the skills needed for building an SD model without external assistance. This will usually be too time-consuming if entrepreneurs and managers in the SME have not learnt SD modeling before. In such cases the SD skills have to be contributed by the facilitators. Nevertheless, people in SMEs are usually capable of understanding an SD model and of giving valuable hints for improvements.

The overall effectiveness of the intervention was, last but not least, a result of a careful reflection and design of the organizational context into which the process was embedded. This refers to the "context loop "of ISM (see Figure 1), which explicitly addresses this aspect. In the GVS case, special care was dedicated to the composition of the project team. The facilitators insisted in having all the key persons from the different functions of the organization as active members of the team. Finally, it proved most valuable to address all the structural and "political" implications of the different design options for all participants as the project went on.

In the light of the evaluation by the participants and the facilitators' own experience, we consider the ISM methodology to be an adequate approach for dealing with strategic issues of a similar kind in SMEs. It allows the participants to attain "better" (shared) mental models of the situations they face and to approach the "requisite variety" in order to manage them better. The SD modeling itself has efficiently supported the creation of useful tools to test and discuss different assumptions with respect to the treated issues. We suggest introducing a preliminary event of about three hours for all the participants of the intervention for future applications of ISM in SMEs. During this event, the facilitators should explain the whole intervention process with examples from other organizations. This would relieve the following workshops from methodological explanations and leave more time for the work on the specific issues of the organization in focus. For the further steps in the transformation process of the FM division, it is very important that the internal champions (CEO, COO) do not prevent the continuation of the project just because the process with the external facilitators has been completed. In the present case, the internal champions apparently know about this threat. For this reason, they have asked one of the facilitators to accompany the next steps of the project.

\section{Notes}

1. The intervention project is linked to Michael Weber's dissertation (supervisors: Professor Bernard Lehmann, Swiss Federal Institute of Technology, and the second author of this article).

2. "Requisite Variety" is a term coined by Ross Ashby in his "Law of Requisite Variety", which says: "Only variety can destroy variety." Variety is a technical term - a measure for, "complexity." The meaning of Ashby's 
theorem is that an effective control system must dispose of a Variety (i.e., a repertory of potential behaviors) that is equivalent to the Variety of the system controlled (Ashby 1964). This is crucial for actors in organizations, especially managers.

3. This map is not entirely symmetric because the two business units of GVS differ in some aspects. In particular, GVS is the major player in the regional market of agricultural inputs, while it is only one competitor among many in the domain of agricultural products. We refrain from discussing details of the map, because they are not essential to the message of this article. However, we include the map to provide a view - albeit somewhat impressionistic - on the procedure used.

4. The costs of inventory are not relevant in the FM division because the amount of supply is the same with and without distribution via the local points of sale.

5. The results of the simulation were also checked with a global calculation of possible financial effects realized with a spreadsheet. This calculation, albeit static, corroborated the positive effects of a turn-off of local points of sale.

\section{References}

Ashby WR. 1964. An Introduction to Cybernetics. Methuen: London.

Barlas Y. 1996. Formal aspects of model validity and validation in system dynamics. System Dynamics Review 12: 183-210.

Barlas Y, Cirak K, Duman E. 2000. Dynamic simulation for strategic insurance management. System Dynamics Review 16: 43-58.

Beer S. 1979. Heart of Enterprise. Wiley: Chichester.

1981. Brain of the Firm, 2nd edn. Wiley: Chichester.

Bickert C. 2001. Die Trennlinien verwischen sich. DLG-Mitteilungen 8: 15-17.

BLW. 2001. Agrarpolitik 2007: Die Weiterentwicklung der Agrarpolitik. Vernehmlassungsunterlage. BLW-Bundesamt für Landwirtschaft, Eidgenössisches Volkswirtschaftsdepartement, Berne, Switzerland. 21 September. 2001.

Burr V. 1995. An Introduction to Social Constructionism. Routledge: London, New York.

Checkland PB. 1981. Systems Thinking, Systems Practice. Wiley: Chichester.

Espejo R. 1993. Management of Complexity in Problem Solving. In Organisational Fitness-Corporate Effectiveness through Management Cybernetics, Espejo R, Schwaninger M (eds). Campus: Frankfurt, New York, 67-92.

Espejo R, Schwaninger M (eds). 1998. To Be And Not To Be, That Is The System. Festschrift for Stafford Beer, CD-ROM. Carl Auer Systeme Verlag: Heidelberg.

Espejo R. et al. 1996. Organizational Transformation and Learning-A Cybernetic Approach to Management. Wiley: Chichester.

Flood RL. 1999. Rethinking the Fifth Discipline-Learning within the Unknowable. Routledge: London.

Forrester JW. 1961. Industrial Dynamics. MIT Press: Cambridge, MA. Now available from Pegasus Communications, Waltham, MA. 
Forrester JW, Senge PM. 1980. Tests for building confidence in system dynamics models, In System Dynamics, Legasto AA, Forrester JW, Lyneis JM (eds). NorthHolland: Amsterdam.

Gomez P, Probst G. 1999. Die Praxis des Ganzheitlichen Problemlösens-vernetzt denken, unternehmerisch handeln, persönlich überzeugen, 3rd edn. Haupt: Bern, Stuttgart, Vienna.

Legasto AA, Forrester JW, Lyneis JM (eds). 1980. System Dynamics. North-Holland: Amsterdam.

Malik F. 1996. Strategie des Managements komplexer Systeme-Ein Beitrag zur Management-Kybernetik evolutionärer Systeme. 5th edn. Haupt: Bern, Stuttgart, Vienna.

Pérez Ríos J, Schwaninger M. 1996. Integrative Systems Modelling: Leveraging complemantarities of qualitative and quantitative methodologies, Proceedings, 1996 International System Dynamics Conference, Richardson GP, Sterman JD (eds). Cambridge, MA, Vol. 2. 431-434.

Probst GJB, Gomez P. 1992. Thinking in networks to avoid pitfalls of managerial thinking. In Context and Complexity, Maruyama M (ed.). Springer: Berlin, Heidelberg, 91-108.

Schmid H. 2001. Entwicklung einer Strategie in einer mittleren Firma des schweizerischen Agribusiness. Nachdiplomarbeit beim Genossenschaftsverband Schaffhausen. Betriebswissenschaften der ETH Zürich, Switzerland.

Schwaninger M. 1995. Computer Based Modelling, Simulation and Graphic Representation of Technology Innovation Networks. Final Report, European Union, Sprint Project DG XIII/D-4. University of St Gallen, Switzerland.

- 1996. Rückgekoppelte Exploration in der Organisationsforschung-Konzept und Anwendung, Brosziewski A (ed.). Vol. Dokumentation Nr. 8. Deutsche Gesellschaft für Soziologie, St, Gallen.

- 1997. Integrative systems methodology: heuristic for requisite variety. International Transactions in Operational Research 4: 109-123.

. 2001. Intelligent organizations: an integrative framework. Systems Research and Behavioral Science 18(2): 137-158.

Schwaninger M, Pérez Ríos J. 1998. ISM-Integrative Systems Methodology: A hybrid Methodology for Applying Cybernetics Cybernetically, Espejo R, Schwaninger M (eds). Carl-Auer-Systeme-Verlag: Wiesbaden.

Sterman JD. 2000. Business Dynamics_-Systems Thinking and Modeling for a Complex World. McGraw-Hill: Boston, MA.

Ulrich H, Probst GJB. 1990. Anleitung zum ganzheitlichen Denken und Handeln: ein Brevier für Führungskräfte. 2. Auflage. Haupt: Bern, Stuttgart.

Vennix JAM. 1996. Group Model Building-Facilitating Team Learning Using System Dynamics. John Wiley: Chichester. 